\title{
Heterotopic, non-functioning masses of nervous tissue in spina bifida cystica
}

\author{
B. E. TOMLINSON \\ From the Department of Pathology, Newcastle General Hospital
}

SYNOPSIS The operative specimens from 160 cases of spina bifida cystica were examined in $\vec{\omega}$ detail. In seven cases the sac contained nervous tissue visible to the naked eye, the removal of which $\overrightarrow{8}$ produced no clinical disability. The form taken by this non-functioning, heterotopic nervous tissue is described.

In the more severe forms of spina bifida cystica in which the spinal cord or nerves extend into the sac (meningomyelocele) or are exposed on the skin surface (myelocele), minute heterotopic nests of glial tissue with or without ependymal canals are frequently found in the surrounding meninges or subcutaneous tissues (Lichtenstein, 1940; Cameron, 1957). Fisher (1950), reviewing a large series of operative specimens from cases of spina bifida cystica, found heterotopic nervous tissue in more than half and stated that in many of these no clinical abnormality was present. Since disabilities almost always accompany meningomyeloceles and are invariable with myeloceles, this finding strongly suggests that simple meningocele sacs, in which the spinal cord and nerves are not involved, may contain heterotopic islands of nervous tissue. Cooper and Kernohan (1951) found that heterotopic glial islands were frequently present in the meninges of the cord and medulla in cases of congenital malformations of the nervous system, and in their series spina bifida was much the most common abnormality. In these and the previous descriptions of Wolbach (1907) and Bailey (1936) the heterotopic glial islands were minute and usually only found in histological preparations.

Few references are available in the literature to the occurrence of visible masses of heterotopic nervous tissue in association with spina bifida cystica. Russell (1949) described a diverticulum of a syringomyelic cord extending into a meningocele sac which existed at a lower level. Doran and Guthkelch (1961) describe the occurrence of a glial extension from between the dorsal columns of the cord into the inner wall of the spina bifida sac. They state that such an extension only occurs in the cervical and dorsal regions and that it may be surgically removed without producing any disability.

In the past eight years a detailed examination of Received for publication 27 May 1965. some 160 excised sacs from cases of spina bifida cystica has been undertaken. Seven cases have been seen in which a mass of nervous tissue, usually in the form of a grey cord not dissimilar to the spinal cord in shape, has been plainly visible in the excised specimen. In the first case it was thought on macroscopic and histological examination that the removed specimen contained part or all of an abnormal spinal cord and that the lesion was therefore a meningomyelocele. Since the patient showed no disability after operation it was clear that the excised tissue was not functioning. The post-operative course in this and in the other six patients has confirmed that cords or masses of non-functioning nervous tissue visible to the naked eye may be present in cases of spina bifida cystica. In some instances neither the spinal cord nor nerves were found in the sac so that it is clear that such nervous masses may occur with simple meningoceles.

It has also been established that these heterotopic masses may accompany spina bifida cystica at any level of the spinal column. Of the seven cases seen, four were associated with cervical spina bifida cystica, one with a dorsal lesion, and two with lumbar or lumbo-sacral lesions.

THE FORM TAKEN BY THE HETEROTOPIC NERVOUS TISSUE

In six cases the heterotopic tissue took the shape of a string or cord, round or oval in cross section, from 5 to $8 \mathrm{~mm}$. in diameter and from $1 \frac{1}{2}$ to $3 \mathrm{~cm}$. long (Fig. 1). In five instances this tissue extended from the neck of the sac towards the dome and had been cut by the surgeon as it entered the sac. In two $\mathbb{D}$ instances it had been seen entering the sac from a deeper level but in the other three it was not seen at operation as it lay beneath the lining of the sac, partly embedded in the fibro-fatty tissue of the sac $\cong$ wall. In the sixth instance the nervous strand lay in 
the dome of the sac with no extension into the neck, and no possible connexion with deeper structures. In the remaining case the nervous tissue formed an irregular, round ball, $1.2 \mathrm{~cm}$. across, attached to the inner lining of the sac, but otherwise similar histologically to the tissue from the other cases.

In all instances the tissue consisted largely of a mass of glial fibres with scanty or moderate numbers of astrocytic nuclei, one or more ependymal canals, and in all but one case, with neurones bearing myelinated axons. In haematoxylin and eosin preparations the tissue, if embedded in the wall of the sac, is not conspicuous, but with glial stains it stands out distinctly from the surrounding tissues. The edge of the tissue is clearly defined, often with a visible pia-like margin and usually separated from the surrounding fibrous tissue by a delicate membrane which is often very vascular and suggestive of arachnoid (Figs. 1 and 2). The pia-like margin may be smooth, but is often made irregular by clefts of vascular tissue entering the glial mass, or by projecting glial spurs. In places the edge has a curious saw-toothed appearance (Fig. 2) where the limiting membrane undulates over densely staining collections of glial fibres. The glial network may be dense throughout but is often more concentrated at the periphery.

In all instances one or more ependymal channels were present. These were usually small, round, or slit-like, well formed and lined completely or almost completely (Fig. 3) by well-preserved ependyma. Occasionally they were larger branching channels, only partially lined with ependymal cells, and in two cases ran the whole length of the tissue.

In all but one instance, neurones of medium and small size were present, in three cases in small numbers, in three in considerable concentrations (Fig. 4); although occurring in any part of the tissue, they were usually more numerous in the centre around the ependymal channels, and often occurred in clumps. Some were shrunken and pyknotic, but others appeared well preserved and axons were easily demonstrated, some of them myelinated.

The vascularity of the tissue differed from case to case and in different parts of the same specimen, but often the tissue was richly supplied by small blood vessels from the surrounding membrane (Figs. 1 and 3 ); in some instances the vessels cut numerous clefts into the nervous tissue, particularly at its periphery, and were grouped into small angiomatous masses (Fig. 1).

\section{ILLUSTRATIVE CASES}

CASE 1, a female, was first seen at age 7 months. She was a healthy, active baby, of normal size and weight and with no evidence of leg or sphincter abnormality. She had an ulcerated meningocele sac over the lumbo-sacral region which measured $6 \mathrm{~cm}$. long and $4 \mathrm{~cm}$. across. A radiograph showed a spina bifida involving most of the lumbosacral vertebrae. At operation the filum terminale was found to enter the lower portion of the sac and this was returned into the spinal canal. After operation there was slight weakness of the right leg for several days but within a fortnight both legs were being normally used and there was no evidence of sphincter abnormality. The child was followed for the next three and a half years, and when last seen, at age 4, she was bright, intelligent, lively and with no motor or sensory defect in the limbs and with normally controlled sphincters. She was dry at night and was considered to be entirely normal.

The removed sac was roughly circular, $5 \mathrm{~cm}$. across after fixation and $3 \mathrm{~cm}$. from the base to the dome. The major part of its cavity was monolocular and it was lined by a smooth membrane. Beneath the inner lining at the neck of the sac was a grey ribbon of tissue, $7 \mathrm{~mm}$. wide $\times$ $2 \frac{1}{2} \mathrm{~mm}$. thick, which extended for $3 \mathrm{~cm}$. into the dome of the sac and terminated in the subcutaneous tissue beneath the skin. Histologically this was a well-defined mass of nervous tissue surrounded by a limiting membrane and consisting of glial fibres and astrocytes, neurones and nerve fibres, some of which were myelinated, and with several small ependymal channels. The neurones were of medium and small size, few in number, though with demonstrably long axons, some of which were myelinated. In addition to this major cord of glial tissue multiple blocks taken from the sac showed two other small glial masses at a distance from the main cord, again several millimetres across, with small ependymal channels and clumps of medium and small neurones.

CASE 2, a female infant, was first seen when a week old because of haemorrhage from the sac of a lumbar meningocele which measured $6 \mathrm{~cm}$. across and was $5 \mathrm{~cm}$. in height. She was a lively, healthy baby with good tone in the legs, and vigorous, full leg movements, no deformities, and no apparent sphincter disturbance There was considerable necrosis of the skin over the sac where large superficial blood vessels were visible. At operation, which was immediately performed, no nervous elements were seen in the sac but the spinal cord was not visualized, there being only a minute communication through the neck of the sac into the spinal subarachnoid space. After operation the child was thought to have slight limitation of leg movement but when seen at 1 year she was completely well and was already standing and attempting to walk in entirely normal fashion. There was no sphincter disturbance and abnormal neurological signs were not elicited. The removed specimen measured $4 \times 6 \mathrm{~cm}$. across at the dome and was $5 \mathrm{~cm}$. high from the dome to the neck. There was an irregular area of ulceration $4 \mathrm{~cm}$. across over the dome. A cavity extended from the narrow opening in the neck of the sac into the dome; no nervous tissue entered the sac at its neck. The sac was multilocular and running across the roof was an oval, grey cord $1 \frac{1}{2} \mathrm{~cm}$. long and $6 \mathrm{~mm}$. across (Fig. 1). Histologically this tissue again consisted of a mass of glial fibres more dense in the sub-pial region than centrally, and with sparse astrocytic nuclei; there were several small ependymal canals, one of which was situated peripherally (Fig. 3). Fairly numerous 


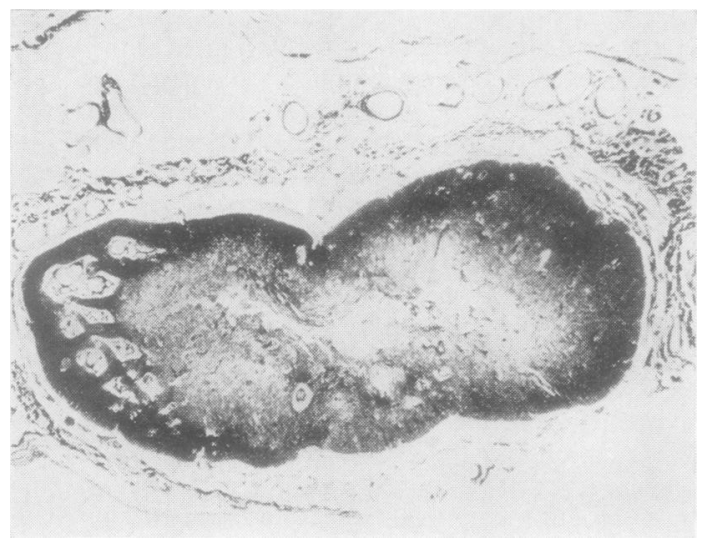

FIG. 1. Transverse section of the heterotopic cord from case 2; the cord is surrounded by delicate, vascular mem. branes. The glial network is dense at the periphery anco more sparse in the central area where neurones and ependymal channels are present. Numerous vasculato bundles invade the periphery of one half of the cordi. Holzer $\times 15$.

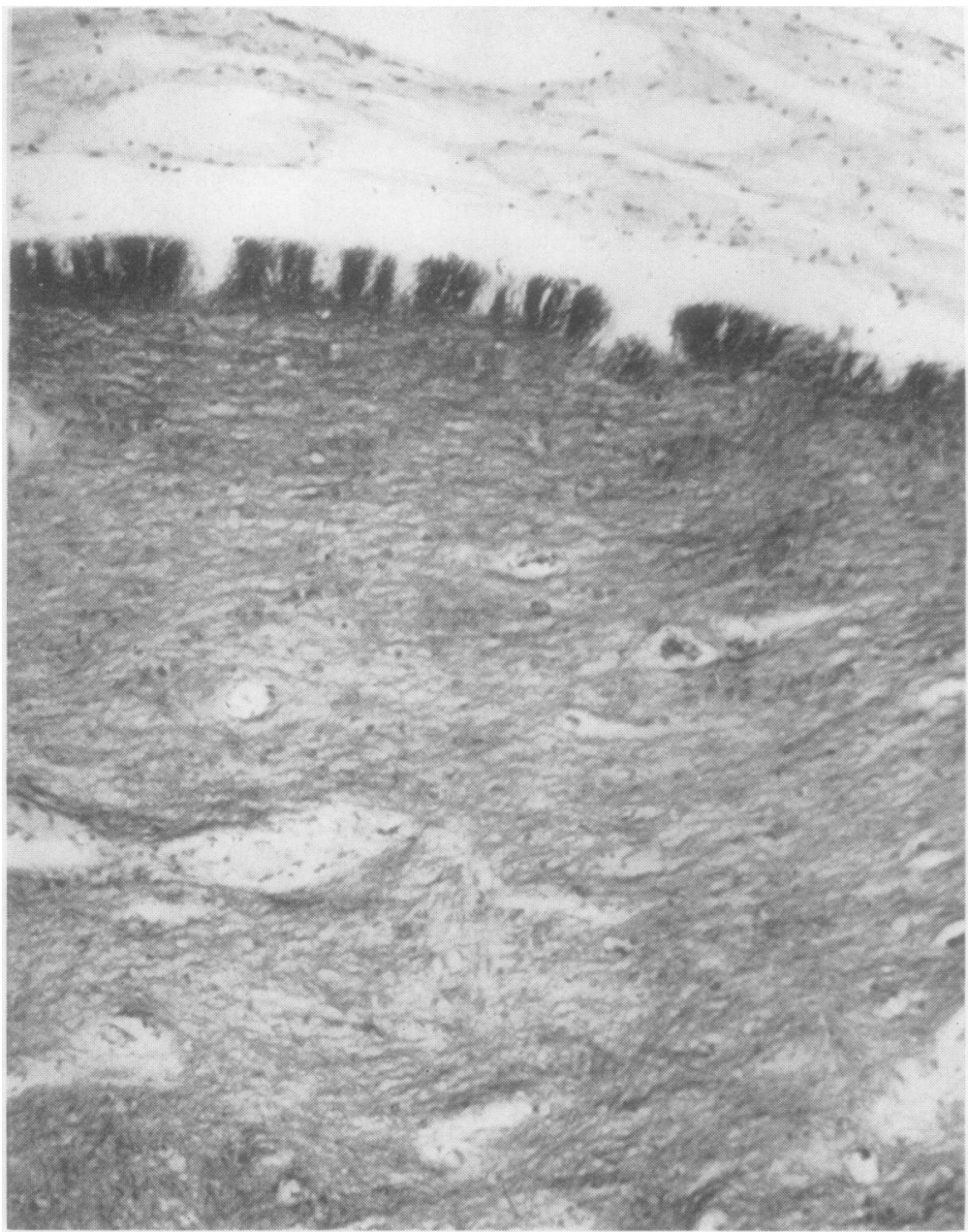

FIG. 2. A delicate arachnoidlike membrane surrounds the glial mass, which in this figure has a marked'sawtoothed' edge, where the glial fibres stain more densely than elsewhere. Mallory's phosphotungstic-acid haematoxylin ? 125. 


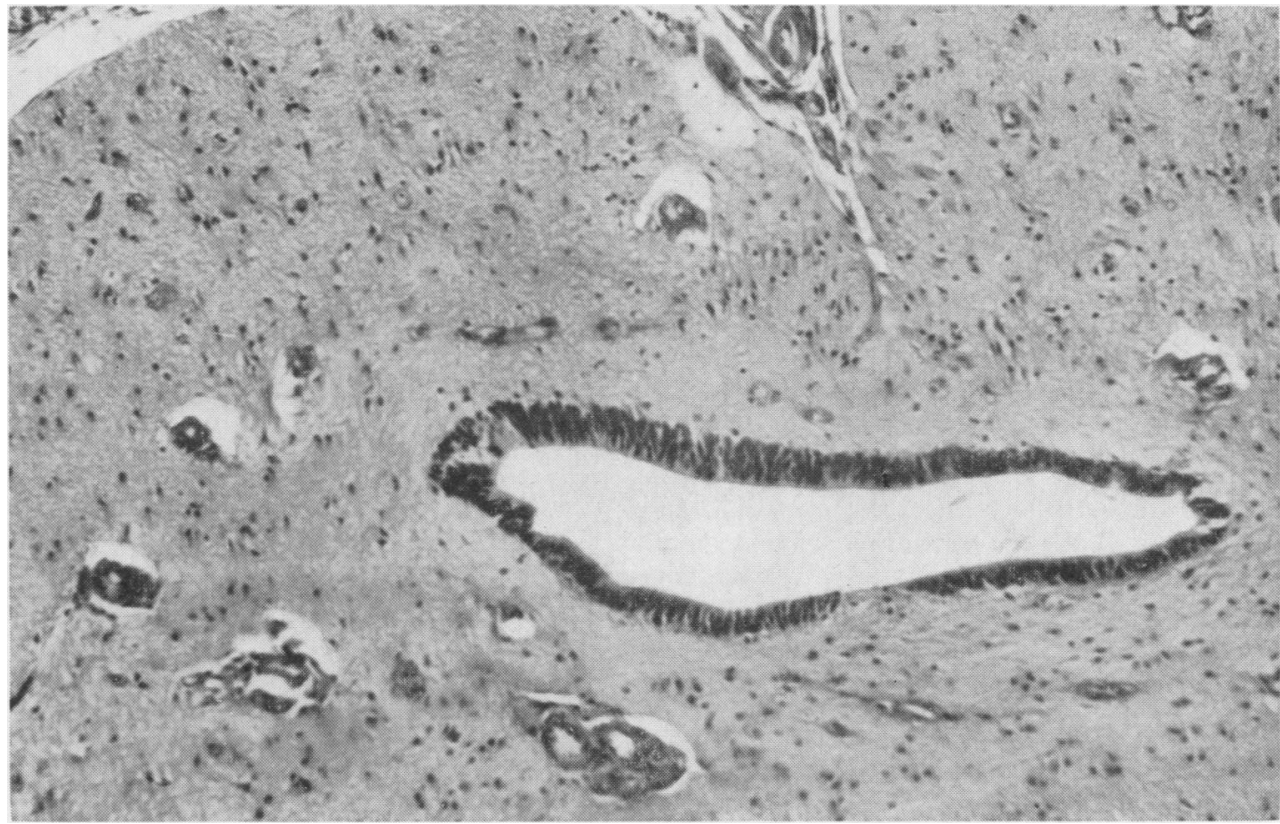

FIG. 3. A well-formed ependymal channel in the periphery of the heterotopic cord in case 2. Numerous blood vessels are present in the glial tissue. The pia-like edge to the tissue is seen in the left upper corner of the figure. Cresyl-fast violet $\times 125$.

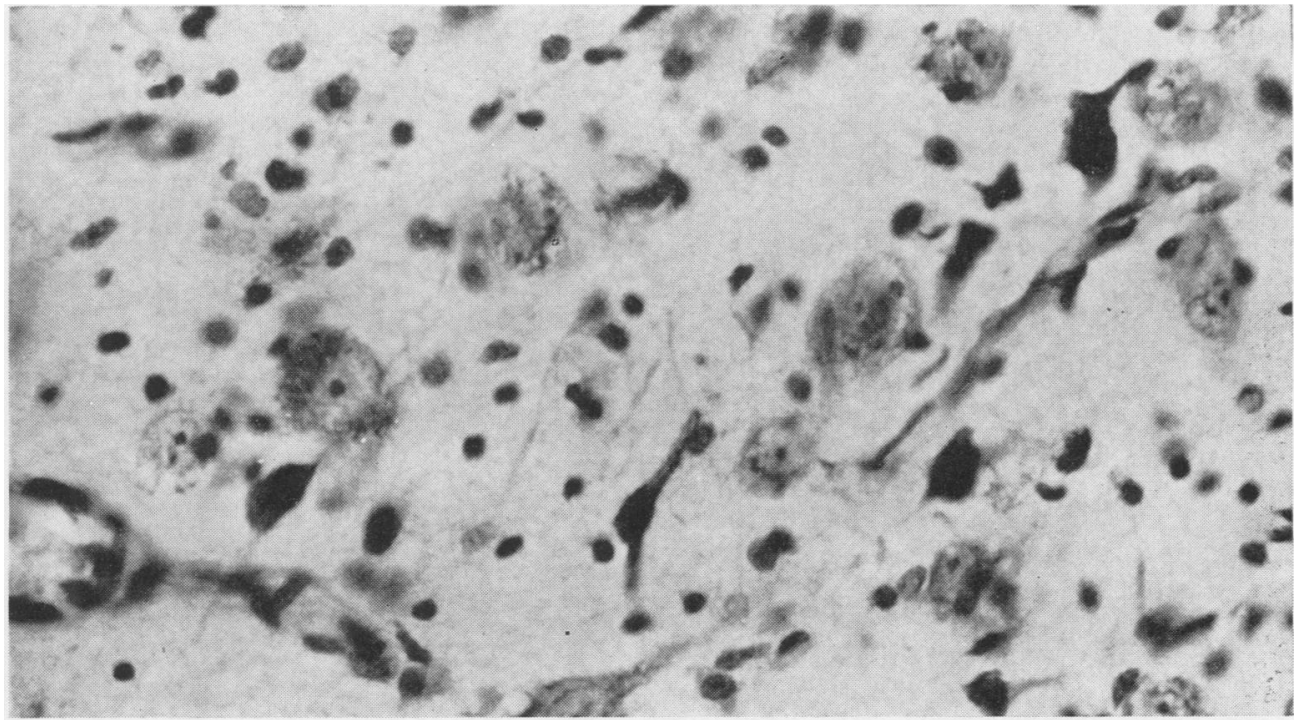

FIG. 4. A dense collection of neurones from the central part of the heterotopic cord in case 5. Cresyl-fast violet $\times 400$. 
medium sized neurones were present, almost all centrally situated, and myelinated fibres were demonstrated. The mass was surrounded by a vascular, arachnoid-like membrane and was cut into in numerous places by groups of thin-walled blood vessels, which made the periphery extremely vascular.

CASE 5, a male, was first seen when 1 day old with a large, pedunculated lower cervical meningocele, $5 \mathrm{~cm}$. across, which was leaking cerebrospinal fluid from a thin central skin area. He was otherwise vigorous and healthy with full arm and leg movements. At operation a fine strand was seen running from the subarachnoid space into the neck of the sac; this was divided where the meningocele was cut across. After operation there was no evidence of spinal cord abnormality but hydrocephalus developed and a Spitz-Holter valve was introduced. The hydrocephalus finally arrested with a head circumference of $24 \frac{1}{4}$ in. and the head was this size at age $2 \frac{1}{4}$ years. The child was then backward in general development but had full and complete arm and leg movements and no abnormal neurological signs in the limbs. In the removed specimen the strand extended from the neck for $2 \mathrm{~cm}$. towards the dome of the sac. It was a flattened, firm, grey cord $8 \times 3 \mathrm{~mm}$. across and consisted largely of glial tissue with a long ependymal canal running its whole length and on either side of which were numerous neurones (Fig. 4) with myelinated axons. Small, separate islands of glial tissue were present in the subcutaneous tissue near the termination of the cord in the sac.

\section{DISCUSSION}

These three cases demonstrate that nervous tissue of the type described may be removed without the development of defects related to the spinal cord; in such cases it is certain the tissue removed is not functioning and likely that no other severe abnormality is present in the spinal cord. In cases 1 and 2 , and in one further case, with a cervical spina bifida (case 4), there was no demonstrable neurological abnormality of any kind after removal of the sac containing the nervous elements, so it is possible that these children will develop completely normally.

Case 5 and two others (cases 6 and 7) with cervical spina bifida developed hydrocephalus after operation. In cases 5 and 7 an Arnold-Chiari malformation was demonstrated radiologically and a Spitz-Holter valve was inserted. In case 7 , slight spasticity of the arms with a wide range of movement was present before the spinal operation and this remained unchanged. Here, therefore, the spinal cord was abnormal at or close to the level of the spina bifida, but the absence of deterioration after operation and the close similarity of the nervous tissue in the sac to that in the other cases strongly suggests that the removed tissue was not functioning. In case 6 , the hydrocephalus which developed post-operatively was mild, and arrested spontaneously with a head circumference of $18 \frac{1}{2}$ in. at 6 months. Four years later the child was bright and intelligent, with normaf hands and arms but she was developing fiat feet and was thought to be slightly unsteady on her feet.

In case 3, with a spina bifida cystica over the third and fourth dorsal vertebrae, the child at age 1 year was entirely normal and remained so for the yearळึ following operation, when slight hypotonia of the arms with some clumsiness of hand movement ${ }^{\text {s }}$ developed. Here, therefore, the removed nervous $\vec{\circ}$ tissue was not functioning but was associated with $a_{-}$ spinal cord abnormality at a higher level.

In cases 2 and 4, neither spinal cord nor nerves were present in the sac, so that the lesion removed? could properly be described as a meningocele. These $\vec{\infty}$ children are symptom free as is case 1 in which the? lesion was technically a meningomyelocele, since the filum terminale entered the deeper part of the saco cavity. Neither nerves nor cord were apparently involved in the sac in cases 5,6 and 7, though all $\vec{Z}$ developed hydrocephalus. In case 3 , the spinal cord우 protruded into the deeper part of the sac, so this was again a meningomyelocele.

It is clear, therefore, that heterotopic, functionless nervous tissue of considerable size may be $\vec{\theta}$ present in meningocele and meningomyelocele sacs o and that its presence does not necessarily indicate other severe abnormalities in the cranio-spinal axis, 을 though in some cases, as would be expected, these are present. Similar heterotopic strands may well occur with myeloceles, but would be more easily overlooked $\frac{}{1}$ if the spinal cord was present in the removed specimen and the child severely disabled.

There is some practical importance in recognizing the tissue described as heterotopic. If it is mistaken $\frac{\vec{F}}{0}$ for part or all of an abnormal spinal cord undue alarm may be felt about the future of an infant $\frac{?}{0}$ who may, nevertheless, possess an intact, normally functioning spinal cord; and in a disabled child, the 3 disabilities may be wrongly attributed to removal of $\delta$ this tissue, whereas they more probably result from other intrinsic abnormalities of the spinal cord.

I wish to thank Mr. L. P. Lassman, Dr. Christine Cooper, and Dr. G. Davison for allowing me access to their excellent clinical records, and Mr. E. Manns for numerous $\mathrm{N}$ histological preparations and the photographs.

\section{REFERENCES}

Bailey, O. T. (1936). Arch. Path., 21, 584.

Cameron, A. H. (1957). J. Path. Bact., 73, 195.

Cooper, I. S., and Kernohan, J. W. (1951). J. Neuropath. exp. Neurol., $10,16$.

Doran, P. A., and Guthkelch, A. N. (1961). J. Neurol. Neurosurg. Psychiat., 24, 331 .

Fisher, R. G. (1950). Spina bifida and cranium bifidum-a clinicopathological study. Ph.D. Thesis, University of Minnesota.

Lichtenstein, B. W. (1940). Arch. Neurol. Psychiat. (Chic.), 44, 792.

Russell, D. S. (1949). Spec. Rep. Ser. med. Res. Coun. (Lond.), no. 265 London.

Wolbach, S. B. (1907). J. med. Res., 16, 495.

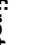

